\title{
Effective Teaching and Learning in Interprofessional Education in Child Welfare
}

\author{
Robert F Whiteley ${ }^{1}$, Judy Gillespie ${ }^{2}$, Cathy Robinson ${ }^{3}$, Wilda Watts ${ }^{4}$, Deb Carter ${ }^{5}$ \\ ${ }^{1}$ University of British Columbia Okanagan, Faculty of Education, Canada \\ ${ }^{2}$ University of British Columbia Okanagan, School of Social Work, Canada \\ ${ }^{3}$ University of British Columbia Okanagan, School of Nursing, Canada \\ ${ }^{4}$ University of Saskatchewan, College of Nursing, Canada \\ ${ }^{5} \mathrm{PhD}$ candidate, University of British Columbia Okanagan, Canada
}

Received: June 3, 2014 Accepted: June 17, 2014 Online Published: October 8, 2014

doi:10.11114/jets.v2i4.427 URL: http://dx.doi.org/10.11114/jets.v2i4.427

\begin{abstract}
This article reports on research regarding interprofessional education (IPE) in child welfare conducted in 2009 and 2010. Pre service nursing, social worker and teacher education candidates participated in a workshop that "exposed" (Charles, Bainbridge \& Gilbert, 2010) students to IPE in child welfare. This paper addresses a gap in literature in IPE in child welfare. Literature in IPE precedes a description of the workshop followed by an explanation of the integrated expert presentation, case study, modeling, reflection and small and large group processes. Results of the survey administered to workshop attendees are presented. Likert scaled questions indicate a high degree of satisfaction with the workshop organization, pedagogy and objectives. Responses to the open-ended questions align closely with the Thistlethwaite and Moran (2010) learning outcomes framework. It is clear that pre-service students learned with, from and about each other's discipline. 2 tables and an extensive reference list are included.
\end{abstract}

\section{Introduction}

A lack of communication amongst professionals working with children at risk has been identified as a significant contributor in child death reviews (Bunting, Lazenbatt \& Wallace 2010; Gove 1995; Laming 2009; Reder \& Duncan, 2003). The importance of interprofessional practice (IPP) amongst nurses, social workers and educators is apparent. What knowledge, skills and attitudes do professionals need to acquire to participate effectively in IPP and where and how do professionals learn about IPP?

Between 2008 and 2011 nursing, social work and education faculty at the University of British Columbia's Okanagan (UBCO) campus offered interprofessional education (IPE) in child welfare workshops to undergraduate nursing, social work and teacher education students. The workshops were an example of what Charles, Bainbridge and Gilbert (2010) consider an "exposure" experience on their "exposure, immersion, mastery" continuum of interprofessional skills. While researching IPE, our experience as professors at UBCO and conversations with scholars and practitioners informs us that IPE in child welfare is virtually absent in undergraduate pre-professional programs.

This article begins with an examination of the literature as it relates to IPE and IPP in child welfare. We then describe our research study focusing on the iterative development of our IPE in Child Welfare Workshop. Next, the methods used in the study are defined followed by the data collection. We conclude with a discussion of the findings.

\subsection{Interprofessional Education to Improve Interprofessional Practice in Child Welfare}

Extant research and literature reporting on IPP and IPE in child welfare is sparse. We discuss the limited research and literature on IPE specifically related to pre-service nursing, social work and teacher education training in postsecondary institutions. The literature review creates a conceptual framework from which university based IPE may be explored and understood.

The conceptual framework includes barriers to IPE; outcomes of pre-certification/pre-licensure IPE (Thistlewaite \& Moran, 2010); and scaffolding a continuum of interprofessional skills (Charles, Bainbridge \& Gilbert, 2010). In addition, three theoretical constructs inform our work: IPE learning outcomes (Thistlewaite \& Moran, 2010), 
scaffolding a continuum of interprofessional skills (Charles, Bainbridge \& Gilbert, 2010) and learning "with, from and about" other professionals (Barr et al, 2005; CAIPE, 2002).

Thistlewaite and Moran (2010) synthesized IPE learning outcomes from 88 sources published between 1988 and 2009 identifying six broad themes in the literature: teamwork, roles/responsibilities, communication, learning/reflection, the patient and ethics/attitudes. Barr, Koppel, Hammick, Reeves and Freeth, (2005) define IPE as situations where two or more professions come together to learn with, from and about each other to improve coordination, collaboration and quality of care, and to counteract the professional, organizational and structural barriers to effective IPP. IPE results in positive interactions that engender mutual trust and support, promotes respect and collaboration between professions and it has been associated with reduced stress, increased job satisfaction, and better recruitment and retention (Barr et al, 2005; Lalayants \& Epstein, 2005; Morrison \& Glenny, 2012; Onandasan \& Reeves, 2005).

University goals (outcomes) for IPE are similar to IPE goals in post-licensure settings-namely to strengthen understanding of other professional roles in patient/client care, to foster skills when working in interprofessional contexts, to 'decenter' cognitive and normative maps grounded in specific professional perspectives, and to strengthen reflexive capacity (Clark, 2006). A specific goal of professional education is to socialize students to the culture of their particular profession (Taylor, 2006) yet Pecukonis, Doyle and Bliss (2008) suggest that IPE is avoided by faculties because of the diverse cultures of the various disciplines and the way disciplinary silos shape curriculum content, professional values and customs and the nature of practice. Within disciplines there may be few faculty with interest or expertise in IPE (Cooper, Spencer-Dawe \& McLean, 2005; Ho, Jervis-Selinger, Gorduas, Frank, Hall, \& Handfield-Jones, 2008) but even where faculty members are interested and able to provide IPE activities, programmatic and institutional barriers may inhibit IPE development (Gilbert, 2005).

Features of interprofessional collaboration (IPC) include development of common goals, trust, and skills to engage in collaborative practice (Thannhauser et al, 2010). Effective IPC requires an understanding of other professions' knowledge, roles, and competencies in comparison to one's own. Pre-service students who are still learning the knowledge, roles, and competencies of their own profession cannot fully develop an understanding of others' roles because they need time to reflect on their developing professional knowledge, roles and competencies. Consequently, pre and post qualification learning outcomes differ (Freeth et al, 2005; Thistlewaite \& Moran, 2010).

IPP is defined as "two or more professions working together as a team with common purpose, commitment and mutual respect" (Freeth, Hammick, Reeves, Koppel \& Barr, 2005, p. 6). Elements of effective IPP include professional knowledge, skills and attitudes reflective of one's professional role, understanding of and respect for the expertise of other professionals, and the ability to communicate and collaborate across professional and organizational cultures (Ewens \& Young, 2008; Hall, 2005; Henneman, Lee \& Cohen, 1995). However, IPP is difficult to facilitate in universities because of the barriers created by professional silos (Brandon \& Knapp, 1999; Fowler, Hannigan \& Northway, 2000; Hall, 2005; Onandasan \& Reeves, 2005). Following certification, professional silos continue to be reinforced by organizational and structural factors within IPP settings (Onandasan \& Reeves 2005; Willumsen, 2008).

Charles, Bainbridge and Gilbert (2010) suggest that interprofessional learning be conceptualized as scaffolding along a continuum of professional skills - exposure, immersion and mastery. During the exposure stage students learn about their own practice while participating in parallel learning experiences with peers from other professions, deepen their understanding of different worldviews and the roles of other professions in addressing health and social care issues, and acquire the knowledge skills and attitudes necessary for the immersion and mastery stages of learning. The immersion stage involves transformational learning where students engage in independent course work and structured practice settings with other disciplines. During the immersion stage students develop a multi-perspective interprofessional worldview encouraged and guided by practicing professionals. At the mastery stage, advanced-level critical thinking skills, in-depth self-reflection and understanding of one's own contributions as well as those of the other practitioners are cultivated.

The three components of the conceptual framework, (barriers, outcomes and the continuum of skills), offer a foci and structure to which our research on the innovative workshops in IPE in child welfare can be linked. The three theoretical constructs, (outcomes, scaffolding and "learning with from and about") provide explanatory devices from which understanding of IPE may be advanced.

\subsection{The Need for Interprofessional Education (IPE) in Child Welfare}

Child welfare has been conceptualized as a continuum spanning promotion, prevention, early intervention, and protection (Prilleltensky, Peirson \& Nelson, 2001). Coordination amongst and collaboration between a range of professionals in achieving positive outcomes for children and families has long been recognized (Jacobson, 2002; Reder \& Duncan, 2003). According to data from the National Child Abuse and Neglect Data System in the USA in 2011, 51 States reported a total of 1,545 fatalities with a lack of coordination or cooperation among different agencies and 
jurisdictions cited as a major issue in child deaths (Child Welfare Information Gateway, 2013). Child death reviews have repeatedly identified IPP issues as factors contributing to these tragedies. These factors include lack of formal protocols, poor coordination, lack of trust amongst professionals, limited understanding of the roles of other professionals, failure to communicate, and failure to respond (Armitage \& Murray, 2007; Department for Education, 2013; Gove, 1995; Hughes, 2006; Laming, 2003).

In several cases child deaths have led to formal legislation designed to improve collaboration, communication and coordination. However, these reforms have met with limited success as inquires in Canada and Great Britain continue to note that professionals go on working in isolation of one another (Hughes, 2006; Laming, 2009). Underreporting of child abuse by family doctors, pediatricians, nurses, teachers and mental health professionals is an ongoing problem (Bunting, Lazenbatt, \& Wallace, 2008). Reder and Duncan (2003) note that professionals do not appear to "think beyond their circumscribed involvement in a case" (p. 83). They suggest that IPC in child welfare would improve if all professionals concerned with child welfare acquired a communication mindset that helped them to think outside their professional silo. Their research assumes that pre-service nursing, social work and teacher education students need to acquire core communication and interprofessional skills in their undergraduate education programs.

Information sharing and communication regarding the abuse and death of children has been compared to a "jigsaw puzzle" with various professionals holding one or more pieces of the puzzle (Barr et al, 2005). Sinclair and Bullock's (2002) review of 40 cases of child abuse identified inadequate knowledge sharing among practitioners resulting from a lack of understanding of confidentiality, consent and referral processes. Reder and Duncan (2003) identified communication issues, with one practitioner failing to notify another of significant information or decisions while Laskey (2008) suggests that teachers experience considerable confusion and stress concerning their role in child protection. Other contributing factors identified included territorialism, lack of clear role identification, unequal status and power, competition for resources, disrespect for other professionals' expertise, and varying professional and organizational priorities, stereotypes, and value systems relating to child abuse and families.

IPP in child welfare is characterized by a high degree of fluidity as the structure, content and focus of collaboration is in a constant state of change. Moreover, IPC occurs with a broad and often shifting range of professionals who operate within a climate of constant differentiation and integration (Willumsen, 2008). Social workers, child and youth care workers, teachers, nurses, lawyers, doctors, psychologists, law enforcement officers, and clergy are some of the many professionals who come together during child welfare/abuse cases. The nature of their IPC may be fleeting or extended. In addition, services for children operate in a context of considerable ambiguity and, because the autonomy of the family is seen as a fundamental component of liberal society, mixed messages may result regarding the identity and role of professionals and the nature of the relationships they develop with one another (Frost \& Robinson 2007; Jones, Chant \& Ward, 2003; Willumsen, 2008).

A recent analysis by Paridis and Reeves (2013) confirms that most IPE initiatives reside in health care related disciplines. Indeed, six of the top tens terms used in the interprofessional literature include "care/caring, nurse/nursing, patient, health, GP/doctor/MD/physician and therapy/therapist/therapeutic" (Pardis \& Reeves, 2013 p. 115). It is inappropriate to assume that health focused IPE can generate the knowledge and skills needed for IPP in child welfare in part because, in the case of child welfare, the roles of the teacher and school represent vital components (Hendry \& Baginsky, 2008; Laskey, 2008; Ødegård 2007). A 2005 UK survey found that 70\% of educators had concerns about a child's welfare while a 2003 study found that $52 \%$ of teachers were involved in a child protection case in the first 12 to 18 months of teaching after qualifying for teacher certification (Hendry \& Baginsky, 2008). Clearly there is a need to include pre-service teacher education students in an undergraduate pre-service exposure focused interprofessional child welfare education program.

\subsection{A Framework for Exposing Pre-Service Students to Interprofessional Practice (IPP) in Child Welfare}

Currently pre-service nursing and teacher education students have little introduction to child welfare practice issues. One of the central learning outcomes in IPE is learning to work effectively in collaborative interprofessional teams (Sims 2011; Stevenson, Seenan, Morlan, \& Smith 2012; Thannhauser, et al 2010). Pre-service students typically learn about roles within their own profession and ought to be exposed to and learning about interprofessionalism while learning with other pre-service students in various pre-service programs (Charles, Bainbridge \& Gilbert, 2010). This learning may occur through course work or through one or a series of workshops. IPE generally relies on cooperative, problem-based, or interdependent learning such as case study, small group work, discussion and active reflection (Barr et al., 2005; Clark, 2006; Cooper, Spencer-Dawe \& MacLean, 2005; Golberg, Koontz, Downs, Uhlig, Kumar, Shah, Clark, Coiner, \& Coiner, 2010). Case study methodology is frequently utilized in IPE (Barr et al, 2005) and IPP (Steinert, 2005).

Our exposure based framework called IPE in Child Welfare Workshop included pre-service nursing, social work and 
teacher education students. For most students this was the first occasion where pre-service students from the three disciplines were brought together to examine IPP. We framed the workshop to provide an interprofessional learning (IPL) activity for students. The aim of this IPL activity was to deepen understanding of one's own professional role in child welfare while also promoting understanding of the differing perspectives and roles of other professions.

Pedagogical methods included placing students in multi-disciplinary small groups of approximately eight to ten students. After a faculty member presented an overview of child welfare issues, pre-service students were introduced to core interprofessional child welfare concepts through two case scenarios and small group work centred on a further child welfare scenario. A large group question/answer and discussion period completed the workshop (Gillespie et al, 2010). The scenarios, while hypothetical, attempted to cover the breadth and complexity of IPP in child welfare while offering opportunities for task-focussed small group work (Lees \& Meyer, 2011).

Modelling of collaborative behaviour was a primary pedagogical approach woven through the workshop. Modeling is the presentation of the values or behaviours of an admired person as an inducement to students to acquire those values or behaviours (Moore, 2001) or, what Guillaume (2000) refers to as learning by example. Modeling also demonstrates appropriate interactions with students, (Orstein \& Lasley, 2001; Selle, Salamon \& Sauer, 2008) and as such was a powerful instructional strategy. It has been found to be effective for learners of all ages and is appropriate in every subject area (Guillaume, 2000). Modeling behaviour affects change because models capture and hold attention, and are imitated (Orstein \& Lasley, 2001). Further, modeling helps shape a healthy group climate, transmit student interest and shape positive listening and communication habits (Guillaume, 2000).

The first two cases were presented, collaboration modeled and rationales discussed by groups of three to four practicing nurses, social workers, and educators. Each of the practitioners came to the workshop highly experienced in their respective fields and in situations demanding IPC. In presenting each scenario, community practitioners modelled IPC and mutual respect as they discussed their own perspectives, priorities and roles and, importantly, listened to each other. Following the presentation and discussion of each case by the community practitioners, students were given time to reflect individually on the case, identify questions issues or areas of confusion, and then discuss their individual reflections within their group.

After the presentation of the first two cases, students worked in their small groups on a third case; the case was accompanied by three to four discussion questions. Community practitioners were present in these small groups and facilitated student review of the case and helped students work through the questions. Once again, the practicing professionals provided modelling within the small groups as they encouraged students from each discipline to participate, collaborate and to listen to one another.

At the conclusion of the small group work students reported back to the large group. A question/answer and discussion period with practitioners followed the reporting out. Each of the scenarios raised a number of issues for students with this portion of the workshop affording students the opportunity to explore interprofessional issues. Common issues and questions included confidentiality, child/youth/family empowerment, cultural respect and cultural competence, and professional boundaries. Community practitioners further modelled collaborative practice by once again listening to one another and reinforcing the importance of working together on behalf of children and families.

In addition to the formal activities, there were opportunities for informal networking prior to and during breaks throughout the workshop. Students typically took advantage of these opportunities to connect with and benefit from the community practitioners' presence and modeling of desired professional behaviours.

The goals and general format of the workshop remained largely unchanged since its inception; however, based on input from community practitioners we made some changes to the scenarios. As well, prior to the 2010 workshop, training in facilitation was provided to a group of student volunteers drawn from each of the three programs. In the workshop that followed, these students assisted with facilitation within the small groups.

In our research we determined the effectiveness of the workshops and innovative problem-based learning pedagogic methods (Hmelo-Silver, 2004) for supporting pre-service students learning of IPP in child welfare.

\section{Methods}

The IPE in Child Welfare workshop was originally delivered in 2008; with 35 pre-service nursing, social work and teacher education students in attendance. Workshop attendance grew to 120 pre-licensure students in 2009 (Gillespie, Whiteley, Watts, Dattolo \& Jones, 2010) and 140 students in 2010. In both 2009 and 2010, a questionnaire was administered to the pre-service nursing, social work and teacher education students attending the workshops.

This article reports on student responses to the questionnaire using a mixed methods design (Cresswell \& Clark 2011; Stepney, Callwood, Ning \& Downing, 2011). Ethical approval for the research was obtained through the University of British Columbia Okanagan's Behavioural Research Ethics Board prior to the first workshop in 2009 and was renewed 
before the second workshop in 2010. First, students were asked to answer seven questions using a five-point Likert scale that rated the effectiveness of the different elements of the workshop. Secondly, they responded to the open-ended question, "What were the most important things you learned today about interprofessional practice in child welfare?"

Workshop packages, distributed as students arrived, included the purpose and protocols of the study, a consent form and a questionnaire. The first part of the questionnaire consisted of seven statements with a five-point Likert scale regarding organization of the workshop, realism of the case examples and usefulness of the small and large group discussions. The five-point scale also asked how the workshop informed practice, learning with, from and about other disciplines, and students' willingness to recommend a similar workshop to other students. The second part of the questionnaire contained three open-ended questions regarding student perceptions of learning and goals for future learning. Finally, one question invited any additional comments. These forms were reviewed with students at the beginning and again at the end of the workshop.

No identifying information was requested from the students in 2009; however, the questionnaire was modified and students attending the 2010 workshop were asked to identify their program of study: nursing, social work (general program), social work (specialty in child welfare), or teacher education. Students were made aware that their completion of the questionnaire and participation in study were voluntary. Students either left the completed forms on their tables at the close of the workshop or placed them in a box near the exit as they left the workshop.

The purposes of the data analysis of the completed questionnaires were 1) to identify students' perceptions towards the workshop and 2) to determine what students felt they had learned about IPP during the workshop. An additional purpose in 2010 was to compare the results between each of the programs of study. To decrease potential bias in the analysis of the qualitative components of the questionnaires, a research assistant was hired to independently code the data. The results were then reviewed and discussed by the research team.

For the first coding analysis, the research assistant coded to specific terms or phrases used by the students. Upon review, the team members felt there were too many statements left as 'uncategorized'. Therefore, a second coding was completed by adding 'like terms' and themes were created. For example, the term 'collaboration' was recognized as a category during the first coding. For the second coding, responses with terms such as 'working with', 'together' and 'consulting' were added to the theme of 'collaboration'. During this process, any discrepancies in coding between the team members and the research assistant were discussed until consensus was reached. In the end a total of thirteen separate themes were used to quantify the data.

\section{Findings}

One hundred of the 122 students who attended the workshop in 2009 completed the questionnaire (82\%) while 98 of 140 students attending the 2010 workshop completed the questionnaire (70\%). Twenty-eight $3^{\text {rd }}$ and $4^{\text {th }}$ year nursing students, $495^{\text {th }}$ year elementary teacher education students and 21 social work students, participated in the 2010 study. Discussed below are the seven Likert-scale statements and one of the open-ended questions. Student responses to the seven Likert-scale statements are summarized in Table 1: "Student Feedback". In all categories average ratings for both 2009 and 2010 workshops ranged from 4.06/5 to 4.72/5.

Table 1. Student Feedback, Education for effective interprofessional practice (IPP) in child welfare

Statement responses $(x / 5)$

\begin{tabular}{llllllll}
\hline & $\begin{array}{l}\text { Well } \\
\text { Organized } \\
\text { Queries: Averages }\end{array}$ & $\begin{array}{l}\text { Realistic } \\
\text { Case } \\
\text { Workshop }\end{array}$ & $\begin{array}{l}\text { Useful } \\
\text { Small Group } \\
\text { Eiscussions }\end{array}$ & $\begin{array}{l}\text { Useful } \\
\text { Large Group } \\
\text { Discussions }\end{array}$ & $\begin{array}{l}\text { My } \\
\text { Informed } \\
\text { Practice }\end{array}$ & $\begin{array}{l}\text { Learned } \\
\text { about Other } \\
\text { Disciplines }\end{array}$ & $\begin{array}{l}\text { Recommend } \\
\text { Workshop to } \\
\text { Others }\end{array}$ \\
\hline 2009 (n=100) & 4.68 & 4.72 & 4.06 & 4.39 & 4.42 & 4.41 & 4.35 \\
\hline 2010 Nursing $(\mathrm{n}=28)$ & 4.59 & 4.64 & 4.32 & 4.43 & 4.29 & 4.68 & 4.32 \\
\hline 2010 Social Work $(\mathrm{n}=21)$ & 4.81 & 4.86 & 4.33 & 4.16 & 4.33 & 4.48 & 4.52 \\
\hline 2010 Education $(\mathrm{n}=49)$ & 4.35 & 4.60 & 4.46 & 4.02 & 4.21 & 4.21 & 4.21 \\
\hline 2010 Total $(\mathrm{n}=98)$ & 4.52 & 4.67 & 4.39 & 4.18 & 4.26 & 4.40 & 4.31 \\
\hline
\end{tabular}

The realism of case examples and usefulness of small and large group discussions were rated very highly by all student participants. Overall, students strongly indicated that their participation in the workshop will inform their practice and that they learned about other disciplines and their work in child welfare. All students indicated that the workshop was well organized and that they would recommend a similar event to other students in their programs. Between the 2009 and 2010 cohorts there was a change in how the small versus the large group discussions were rated; in 2009 the large group was seen as more helpful than the small groups, while in 2010 students perceived the small groups to be more 
helpful in their learning than the large group.

The second part of the analysis included the students' written responses to the open-ended question "what were the most important things you learned today about interprofessional practice in child welfare?" The coded results quantifying these responses are summarized in Table 2: Student Perceptions of Learning.

Table 2. Student Perceptions of learning: "what were the most important things you learned today about interprofessional practice in child welfare?" Themes based on Thistlethwaite and Moran. (2010, p. 511)

\begin{tabular}{|c|c|c|c|c|c|}
\hline Themes & $\begin{array}{l}2009 \\
\text { Comments }\end{array}$ & 2010 Nursing & $\begin{array}{l}2010 \\
\text { Social Work }\end{array}$ & $\begin{array}{l}2010 \\
\text { Education }\end{array}$ & 2010 Total \\
\hline $\begin{array}{l}\text { Teamwork: } \\
\text { Collaboration + Professional } \\
\text { Connections + Team }\end{array}$ & 38 & 20 & 14 & 27 & 61 \\
\hline $\begin{array}{l}\text { Roles/Responsibilities: } \\
\text { Resources/Services } \quad+\text { Roles }\end{array}$ & 32 & 13 & 11 & 19 & 43 \\
\hline $\begin{array}{l}\text { Learning/ Reflection: } \\
\text { Content of Workshop } \\
\text { + Disciplines: Importance of } \\
\text { Disciplines + Disciplines: } \\
\text { Learned about other disciplines } \\
\text { + Support }\end{array}$ & 7 & 4 & 2 & 9 & 15 \\
\hline The Patient: & 3 & 3 & 1 & 8 & 12 \\
\hline $\begin{array}{l}\text { Communication: } \\
\text { Communication }+ \text { Reporting }\end{array}$ & 6 & 5 & 2 & 4 & 11 \\
\hline Ethics/Attitudes: & 2 & 0 & 4 & 1 & 5 \\
\hline One-offs & 5 & 3 & 1 & 7 & 11 \\
\hline Totals & 93 & 48 & 35 & 75 & 158 \\
\hline
\end{tabular}

As indicated in Table 2, student comments with respect to "Collaboration + Professional Connections + Team" appeared most frequently in both 2009 (40.8\% of student responses) and 2010 (38.6\% of student responses). Interprofessional collaborative practice, a blend of IPP and IPC was represented in student comments such as, "it is vital to the outcome of the care plan and the welfare of the child involved to collaborate professionally with other disciplines for the best possible outcomes" (2009 student \#14); "so much collaboration and teambuilding is involved when it comes to working with children" (2010 teacher education student \#83); and a comment from a 2010 nursing student (\#02) who recognized the "substantial benefits that can come for so many professionals working together to improve the well-being of a individual/child."

The next most common learning comments identified by the students in both 2009 (34.4\% of student responses) and 2010 (27.2\% of student responses) fell under the theme of "roles and responsibilities." This theme was represented in remarks such as the recognition of, "(British Columbia Ministry of Children and Family Development) MCFD and their role in a child's welfare and what they do and are responsible for" (2009 student \#03) and "what my role as a teacher will be, to focus on strength, empowerment and relationship" (2009 student \#24). Comments made in 2010 were similar: a nursing student commented that "there must be an understanding of the roles of other professionals who are involved" (\#24) while a social work student noted s/he had to be aware of "the obligations that we have as professionals" (\#36), while a teacher education student was reminded to "always take into consideration other perspectives" (\#52). It is evident from this finding that students acquired an understanding of the differing perspectives and roles of other professionals.

The remaining themes [learning/reflection; the patient; communication; ethics/attitudes; and "one-offs"] each received less than $10 \%$ of student comments. However, we were intrigued with the depth of understanding suggested by some of the comments. For example, a 2010 nursing student commented "we use the same words but they have different meanings depending upon what discipline you're coming from "(\# 16) while a social work student was "impressed at the level of practice occurring in the community" (\# 37) and a teacher education student learned about the "various programs that can assist in support in cases of child/minor welfare" (\# 62). All students in both years learned from practitioners and each other leading a 2009 student to remark on the "vastness and interrelation of the support network available to children and youth."

Pre-service nursing, social work and teacher education students learned some fundamental concepts associated with IPP as approximately $70 \%$ of students participating in the workshops acquired knowledge about the importance of collaboration and team work when addressing issues of child welfare. We are left to wonder at what point in their 
training and from whom, other than ourselves, pre-service students would acquire interprofessional knowledge and understanding.

\section{Discussion}

At the University of British Columbia's Okanagan campus pre-service nursing, social work and teacher education students learned with, from and about their peers and their disciplines by working in interprofessional teams where they addressed questions based on case scenarios. As a key component of the conceptual framework the authors found students, at the exposure stage of IPE, were provided with opportunities to participate in shared learning experiences with peers from other professions with the desired outcome that students gain a deeper understanding of their own profession while gaining appreciation of the roles of other professions (Charles et al., 2010, p. 13). This was evidenced by comments included in the roles/responsibilities category that support our claim that students have acquired some understanding of other professions' roles and responsibilities. Based on the $74 \%$ of 2009 and $65.6 \%$ of 2010 responses in the "collaborative practice/teamwork" and "roles/responsibilities" categories [see Table 2] it is apparent that pre-service nursing, social work and teacher education students are being exposed to each other's professional work.

The authors have begun to decenter student perspectives (Clark 2006) and move pre-service students beyond "their circumscribed involvement in a case" (Reder \& Duncan 2003) towards an appreciation of the work and culture of their own and other professionals as well (Taylor 2006). When pre-service students identify a child welfare case in their practice they will recognize they are not isolated from other professionals working with children in need. This is especially true for teachers who play a vital role in the identification of child welfare issues in their classrooms and schools (Laskey 2008). Further, social workers, nurses and teachers who have taken the workshops have heightened awareness of child welfare issues and may begin to investigate protocols and policies that may improve trust and enhance coordination amongst professionals.

Pre-service nursing, social work and teacher education students observed practitioners who modelled appropriate IPP through case study experiences. Further, pre-service students participated in a lecture, individual reflection and small and large group discussion activities connected specifically to child welfare cases. The literature supports these effective pedagogical techniques (see for example Barr et al 2005; Clark 2006; Cooper et al 2005; Golberg et al 2010; Thannhauser et al 2010).

Case study methodology is frequently used in mixed method research design (Cresswell \& Clark 2011) and in IPE (Barr et al, 2005) and practice (Steinert, 2005). Involving practitioners in the development and review of case studies contributed significantly to the pragmatic "real world" quality of the case studies. The authors worked collaboratively with practicing nurses, social workers and educators to review and develop case study scenarios prior to conducting the 2009 workshop. This significantly improved the case studies and may have positively impacted our results. The cases were recognized as a strength by all students, especially social work students. Guided by principles of problem-based learning (Hmelo-Silver, 2004), our goal to develop realistic case scenarios, while hypothetical, clearly stimulated student interest. Based on the survey results it is evident that the scenarios effectively addressed both the breadth and complexity of IPP in child welfare.

The Thistlethwaite and Moran (2010) framework identified six broad IPE learning outcomes. Arranged by frequency of use these are: teamwork, roles/responsibilities, communication, learning/reflection, the patient and ethics/attitudes. Applying the Thistlewaite and Moran framework to student responses to "what were the most important things you learned today about interprofessional education in child welfare" was purely serendipitous. We were not aware of nor were we planning to categorize student comments according to the Thistlewaite and Moran framework prior to conducting analysis. However, with the congruencies of both the titles of the categories and the number of responses that fit within those categories amongst our outcomes and the Thistlewthwaite and Moran framework, we realised that the learning outcomes for the IPE in Child Welfare Workshop mapped to the majority of the accepted health related IPE learning outcomes and fit within international standards.

Time for students to reflect on their learning following each case was provided, however we did not have a method to capture and report on learning occurring during and immediately following case work or what Schon (1987) refers to as "reflection-in-action" and "reflection-on-action". We recommend incorporating opportunities for students to reflect on their practice in future exposure based frameworks.

\section{Conclusion}

Clearly, pre-service students attending our IPE in Child Welfare Workshop considered the event to be successful. The use of problem based learning and case study pedagogical method seems to support a model that provides pre-service nursing, teacher education and social work students' exposure to IPP in child welfare. The theoretical constructs worked as explanatory devices. Involving practitioners in development of cases contributed significantly to the realism of the 
cases and helped to scaffold student learning. The objectives for pre-service students to understand their role in IPP, to learn with from and about other professionals, and acquire knowledge of the different perspectives and roles of other professions involved in child welfare issues was achieved. The case study inquiry method with practitioners modeling interprofessional behaviours and attitudes worked very well.

Faculty members apply their knowledge of pedagogy and instruction to facilitate dialogue and critical thinking, while social workers, nurses and teachers bring a 'real world' understanding of IPP issues to the event. This mutual exchange deepens and enriches the experience, not only for students, but also for faculty and practitioners. With significant juggling of classes, support of colleagues and administrators and a desire and interest in IPE in child welfare, faculty members at UBC's Okanagan campus were able to overcome the educational, programmatic and institutional barriers that inhibit IPE (Gilbert, 2005). Our learning mirrored that of our students as we successfully moved beyond our professional silos and adopted a professional mindset that allowed us to learn with, from and about each other's work. Like Stepney et al (2011) suggests for students, we too established a strong commitment to collaborative practice.

The three conceptual approaches to IPE evident in our research (Charles et al, 2010; Freeth et al, 2005; Thistlethwaite \& Moran 2010) are generally oriented towards health disciplines, rather than our focus of child welfare. We find ourselves (and our research) at a possible crossroads. Our research in IPE in child welfare may be subsumed in health oriented IPE theory and we may choose to pursue other research issues prevalent in IPE and / or child welfare. Alternatively, we may consider continuing the development of a distinct IPE in child welfare model. For now, what we know is our interprofessional learning mirrored that of our students as we successfully moved beyond our professional silos and adopted an interprofessional mindset that allowed us to learn with, from and about each other's work. Similar to Stephney et al's (2011) suggestion that students establish a stronger commitment to IPC when exposed to IPE, we are committed within our professional practices to IPE and IPC as we focus on child welfare issues..

\section{References}

Armitage, A., \& Murray, E. (2007). Thomas Gove: A commission of inquiry puts children first and proposed community governance and integration of services. In L. Foster and B. Wharf (Eds.). People, politics and child welfare in British Columbia, 139-157. Vancouver: UBC Press.

Barr, H., Koppel, I., Reeves, S., Hammick, M., \& Freeth, D. (2005). Effective interprofessional education: Argument, assumption and evidence. Oxford: Blackwell Publishing. http://dx.doi.org/10.1002/9780470776445

Brandon, R., \& Knapp, S. (1999). Interprofessional education and training: Transforming professional preparation to transform human services. American Behavioural Scientists, 42(5), 876-891. http://dx.doi.org/10.1177/00027649921954453

Bunting, L., Lazenbatt, A., \& Wallace I. (2010). Information sharing and reporting systems in the UK and Ireland: Professional barriers to reporting child maltreatment concerns. Child Abuse Review, 19, 187-202. http://dx.doi.org/10.1002/car.1076

CAIPE (Centre for the advancement of interprofessional education). (2002). http://www.caipe.org.uk/about-us/defining-ipe/

Charles, G., Bainbridge, L. \& Gilbert, J. (2010). The University of British Columbia model of interprofessional education. Journal of Interprofessional Care, 24(1), 9-18. http://dx.doi.org/10.3109/13561820903294549

Child Welfare Information Gateway. (2013). Child abuse and neglect fatalities 2011: statistics and interventions. Washington DC: Children's Bureau. http://www.education.gov.uk/a00227978/scr-daniel-pelka

Clark, P. (2006). What would a theory of interprofessional education look like? Some suggestions for developing a theoretical framework for teamwork training. Journal of Interprofessional Care, 20(6), 577-589. http://dx.doi.org/10.1080/13561820600916717

Cooper, H., Spencer-Dawe, E., \& McLean, E. (2005). Beginning the process of teamwork: Design, implementation and evaluation of an interprofessional education intervention for first year undergraduate students. Journal of Interprofessional Care, 19(5), 492-508. http://dx.doi.org/10.1080/13561820500215160

Cresswell, J., \& Clark, V. (2011). Designing and conducting mixed methods research (2 ${ }^{\text {nd }}$ ed.). Thousand Oaks: Sage Publications.

Department for Education. (2013). Serious case review report: Daniel Pelka. London UK: Department for Education.

Ewens, A., \& Young, G. (2008). Collaboration beyond champions. In Howkins, E., \& Bray, J., (Eds.), Preparing for interprofessional teaching: Theory and practice 87-96. Oxford: Radford.

Fowler, P., Hannigan, B., \& Northway, R. (2000). Community nurses and social workers learning together: A report on 
an interprofessional education initiative in South Wales. Health and Social Care in the Community, 8(3), 186-191. http://dx.doi.org/10.1046/j.1365-2524.2000.00241.x

Freeth, D., Hammick, M., Reeves, S., Koppel, I., \& Barr, H. (2005). Effective interprofessional education: Development, delivery and evaluation. Oxford: Blackwell. http://dx.doi.org/10.1002/9780470776438

Frost, N., \& Robinson, M. (2007). Joining up children's services: Safeguarding children in multi-disciplinary teams. Child Abuse Review, 16, 184-199. http://dx.doi.org/10.1002/car.967

Gilbert, J. (2005). Interprofessional learning and higher education structural barriers. Journal of Interprofessional Care. 19(1), 87-106. http://dx.doi.org/10.1080/13561820500067132

Gilbert, J., (2010). Editorial. Journal of Interprofessional Care, 24(5), 473-474. http://dx.doi.org/10.3109/13561820.2010.487723

Gillespie, J., Whiteley, R., Watts, W., Dattolo. L., \& Jones, D. (2010). Interprofessional education in child welfare: A university-community collaboration between nursing, education, and social work. Relational Child and Youth Care Practice, 23(1), 5-15.

Golberg, L., Koontz, J., Downs, D., Uhlig, P., Kumar, N., Shah, S., \& Coiner, C. (2010). Infusing an inter-professional and inter-university perspective into healthcare education. Higher Education Research and Development, 29(4), 421-431. http://dx.doi.org/10.1080/07294361003601875

Gove, T. (1995). Executive summary: Report of the Gove inquiry into child protection in British Columbia. Victoria: Queen's Printer.

Guillaume, A. (2000). Classroom teaching: A primer for new professionals. Upper Saddle River: Merrill.

Hall, P. (2005). Interprofessional teamwork: Professional cultures as barriers. Journal of Interprofessional Care, 19, 188-196. http://dx.doi.org/10.1080/13561820500081745

Hendry, E., \& Baginsky, W. (2008). Training school staff to safeguard children and young people. In M. Baginsky (Ed.) Safeguarding children and schools, 151-165. London: Jessica Kingsley.

Henneman, E. A., Lee, J. L., \& Cohen, J. I. (1995). Collaboration: A concept analysis. Journal of Advanced Nursing, 21, 103-109. http://dx.doi.org/10.1046/j.1365-2648.1995.21010103.x

Hmelo-Silver, C. (2004). Problem-based learning: What and how do students learn?. Educational Psychology Review, 16(3), 235-247. http://dx.doi.org/10.1023/B:EDPR.0000034022.16470.f3

Ho, K., Jarvis-Selinger, S., Borduas, F., Frank, B., Hall, P., \& Handfield-Jones, R. (2008). Making interprofessional education work: The strategic roles of the academy. Academic Medicine, 83(10), 934-940. http://dx.doi.org/10.1097/ACM.0b013e3181850a75

Howkins, E., \& Bray, J., (Eds.) (2008). Preparing for interprofessional teaching: Theory and practice. Oxford: Radford publishing.

Hughes, T. (2006). BC children and youth review. An independent review of BC's child protection systems. Victoria: Queens Printer.

Jacobson, M. (2002). Local realities: A frontier perspective on child protection practices. Child Welfare, 81, 737-756.

Jones, H., Chant, E., \& Ward, H. (2003). Integrating children's services: A perspective from England. In N. Trocme, D. Knoke \& C. Roy (Eds.). Community collaboration and differential response: Canadian and international research and emerging models of practice, 119-131. Ottawa, ON: Centre of Excellence for Child Welfare, Child Welfare League of Canada.

Lalayants, M., \& Epstein, I. (2005). Evaluating multidisciplinary child abuse and neglect teams: A research agenda. Child Welfare, 84(4), 433-458.

Laming, L. (2003). The Victoria Climbie Inquiry: Report of an inquiry by Lord Laming, Cm 5730. London: The Stationary Office.

Laming, L. (2009). The protection of children in England: A progress report. London: The Stationary Office. http://publications.everychildmatters.gov.uk/

Laskey, L. (2008). Training to safeguard: The Australian experience. In M. Baginsky (Ed.) Safeguarding children and schools, 166-178. London: Jessica Kingsley.

Lees, A., \& Meyer, E. (2011). Theoretically speaking: Use of a communities of practice framework to describe and evaluate interprofessional education. Journal of Interprofessional Care, 25(2), 84-90. 
http://dx.doi.org/10.3109/13561820.2010.515429

Moore, K. (2001). Classroom teaching kills (5th ed.). Boston: McGraw Hill.

Morrison, M., \& Glenny, G. (2012). Collaborative inter-professional policy and practice: In search of evidence. Journal of Education Policy, 27(3), 367-386. http://dx.doi.org/10.1080/02680939.2011.599043

Newell-Jones, K., \& Lord, M., (2008). A learning and teaching framework for interprofessional learning. $13-26$.

Howkins, E., \& Bray, J., (Eds.). Preparing for interprofessional teaching: Theory and practice. Oxford: Radford.

Ødegård, A. (2007). Time used on interprofessional collaboration in child mental health care. Journal of Interprofessional Care, 21(1), 45-54. http://dx.doi.org/10.1080/13561820601087914

Onandasan, I., \& Reeves, S. (2005). Key elements of interprofessional education. Part 2: Factors, processes and outcomes. Journal of Interprofessional Care, (Supp), 1, 39-48. http://dx.doi.org/10.1080/13561820500081703

Orstein, A., \& Lasley, T. (2001). Strategies for effective teaching (3rd ed.). Boston: McGraw Hill.

Pardis, E., \& Reeves, S. (2013). Key trends in interprofessional research: A macrosocialogical analysis from 1970 to 2010. Journal of Interprofessional Care, 27, 113-122.

Pecukonis, E., Doyle, O., \& Bliss, D. (2008). Reducing barriers to interprofessional training: Promoting interprofessional cultural competence. Journal of Interprofessional Care, 22(4), 417-428. http://dx.doi.org/10.1080/13561820802190442

Prilleltensky, I., Peirson, L., \& Nelson, G. (2001). Mapping the terrain: Framework for promoting family wellness and preventing child maltreatment, 3-40.

Prilleltensky, G. Nelson \& L. Peirson (Eds.), Promoting family wellness and preventing child maltreatment: Fundamentals for thinking and action Toronto: University of Toronto Press.

Reder, P., \& Duncan, S. (2003). Understanding communication in child protection networks. Child Abuse Review, 12, 82-100. http://dx.doi.org/10.1002/car.787

Schön, D., (1987). Teaching artistry through reflection-in-action. In Educating the reflective practitioner22-40. San Francisco, CA: Jossey-Bass Publishers.

Selle, K., Salamon, R., \& Sauer, J. (2008). Providing interprofessional learning through interdisciplinary collaboration: The role of "modeling". Journal of Interprofessional Care, $22 \quad(1), \quad 85-92$. http://dx.doi.org/10.1080/13561820701714755

Sims, D. (2011). Achieving collaborative competence through interprofessional education. Lessons learned from joint training in learning disability nursing and social work. Social Work Education, 30(1), 98-112. http://dx.doi.org/10.1080/02615471003748056

Sinclair, R., \& Bullock, R. (2002). Learning from past experience - A review of serious case reviews. London: Department of Health.

Stanley, N., Manthorpe, J., \& Talbot, M. (1998). Developing intrprofessional learning in child protection at the qualifying level. Journal of Interprofessional Care, 12(1), 33-41. http://dx.doi.org/10.3109/13561829809014085

Steinert, Y. (2005). Learning together to teach together: Interprofessional education and faculty development. Journal of Interprofessional Care, 19(1), 60-75. http://dx.doi.org/10.1080/13561820500081778

Stepney, P., Callwood, I., Ning, F., \& Downing, K. (2011). Learning to collaborate: A study of nursing students' experience of inter-professional education at one UK university. Educational Studies, 37(4), 419-434. http://dx.doi.org/10.1080/03055698.2010.539669

Stevenson, K., Seenan, C., Morlan, G., \& Smith, W. (2012). Preparing students to work effectively in interprofessional and social care teams. Quality in Primary Care, 20(3), 227-230.

Thannhauser, J., Russell-Mayhew, S., \& Scott, C. (2010). Measures of interprofessional education and collaboration. Journal of Interprofessional Care, 24(4), 336-349. http://dx.doi.org/10.3109/13561820903442903

Thistlethwaite, J., \& Moran, M. (2010). Learning outcomes for interprofessional education (IPE): Literature review and synthesis. Journal of Interprofessional Care, 24(5), 503-515. http://dx.doi.org/10.3109/13561820.2010.483366

Whiting, M., Scammel, A., \& Bifulco, A. (2008). The health specialist initiative: Professionals' views of a partnership initiative between health and social care for child safeguarding. Qualitative Social Work, 7(1), 99-117. http://dx.doi.org/10.1177/1473325007086418 
Willumsen, E. (2008). Interprofessional collaboration - a matter of differentiation and integration? Theoretical reflections based in the context of Norwegian childcare. Journal of Interprofessional Care, 22(4), 352-363. http://dx.doi.org/10.1080/13561820802136866

\section{(c) $\mathbf{E Y}$}

This work is licensed under a Creative Commons Attribution 3.0 License. 